\title{
The genetic legacy of extirpation and re-colonization in Vancouver Island wolves
}

\author{
Violeta Muñ oz-Fuentes \& Chris T. Darimont \&

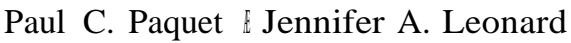

\begin{abstract}
Hybridization between wild and domestic species is of conservation concern because it can result in the loss of adaptations and/or disappearance of a distinct taxon. Wolves from Vancouver Island, British Columbia (Canada), have been subject to several eradication campaigns during the twentieth century and were considered virtually extirpated between 1950 and 1970. In this study, we use control region mitochondrial DNA sequences and 13 autosomal
\end{abstract}

Electronic supplementary material The online version of this article (doi:10.1007/s10592-009-9974-1) contains supplementary material, which is available to authorized users.

\author{
V. Muñoz-Fuentes (\&) · J. A. Leonard \\ Department of Evolutionary Biology, Uppsala University, \\ Norbyvägen 18D, 75236 Uppsala, Sweden \\ e-mail: Violeta.Munoz@ebc.uu.se

\section{T. Darimont} \\ Environmental Studies Department, University of California, \\ 405 ISB. 1156 High Street, Santa Cruz, CA 95064, USA \\ e-mail: darimont@ucsc.edu \\ C. T. Darimont · P. C. Paquet \\ Raincoast Conservation Foundation, PO Box 77, \\ Denny Island, BC V0T 1B0, Canada \\ P. C. Paquet \\ Faculty of Environmental Design, University of Calgary, \\ Calgary, AB T2N 1N4, Canada \\ e-mail: ppaquet@baudoux.ca

\section{J. A. Leonard} \\ Center for Conservation and Evolutionary Genetics, National \\ Zoological Park, Smithsonian Institution, 3001 Connecticut \\ Avenue NW, Washington, DC 20008-0551, USA \\ e-mail: Jennifer.Leonard@ebc.uu.se
}

\section{J. A. Leonard}

Estación Biológica de Doñana-CSIC, Avd. Americo

Vespucio s/n, 41092 Sevilla, Spain microsatellite loci to characterize Vancouver Island wolves as well as dogs from British Columbia. We observe a turnover in the haplotypes of wolves sampled before and after the 1950-1970 period, when there was no permanent wolf population on the island, supporting the probable local extinction of wolves on Vancouver Island during this time, followed by re-colonization of the island by wolves from mainland British Columbia. In addition, we report the presence of a domestic dog mtDNA haplotype in three individuals eliminated in 1986 that were morphologically identified as wolves. Here we show that Vancouver Island wolves were also identified as wolves based on autosomal microsatellite data. We attribute the hybridization event to the episodically small size of this population during the recolonization event. Our results demonstrate that at least one female hybrid offspring, resulting from a cross of a male wolf and a female dog or a female hybrid pet with dog mtDNA, successfully introgressed into the wolf population. No dog mtDNA has been previously reported in a population of wild wolves. Genetic data show that Vancouver Island wolves are distinct from dogs and thus should be recognized as a population of wild wolves. We suggest that the introgression took place due to the Allee effect, specifically a lack of mates when population size was low. Our findings exemplify how small populations are at risk of hybridization.

Keywords Allee effect - Canada - Canis - Domestic dog · Historical DNA · Hybridization · Introgression ·

Microsatellites · mtDNA · Museum specimens · Wolf

Introduction

Hybridization among canids may be associated with human-induced population fragmentation, density alterations 
and/or disruption of their social structures. In such situations it could be difficult for individuals to find appropriate mates (one cause of the Allee effect; Allee 1931; Stephens et al. 1999), making members of another closely related species, including free-ranging domestic dogs (Canis familiaris), appear as suitable partners.

Hybridization between wild canids and domestic dogs has been reported to occur sporadically. Adams et al. (2003) reported the presence of a domestic dog mtDNA haplotype in coyotes (C. latrans), likely due to the presence of only young coyote males released for hunting. Gottelli et al. (1994) reported the presence of hybrids in the very fragmented and small Ethiopian wolf (C. simensis) population resulting from the cross of female wolves and male dogs. Hybrids of grey wolves and dogs have been reported both by sightings and genetic studies. Young and Goldman (1944) hypothesized that where wolves were decreasing they might hybridize with dogs. Mendelssohn (1982), Boitani (1982) and Bibikov (1982) reported morphological evidence of hybrids in Israel, Italy and the USSR, respectively. Vilà et al. (2003a) confirmed the presence of F1 hybrids resulting from the cross of a female grey wolf and a male dog in the very small and recently re-founded Scandinavian population. Although nuclear genetic data have provided evidence for hybridization in Bulgaria, Italy, Latvia, Spain, Sweden and other regions (e.g. Randi et al. 2000; Andersone et al. 2002; Randi and Lucchini 2002; Vilà et al. 2003a; Verardi et al. 2006), no dog mtDNA has been observed to have introgressed into any wolf population. This suggests either that hybridization is asymmetric or that female F1 hybrids with dog mtDNA do not reproduce because they do not survive to adulthood or are not able to socialize into wolf populations (i.e., become reproductive females; Vilà and Wayne 1999; Randi et al. 2000). Hybridization raises several conservation concerns, such as loss of a species' or populations' specific adaptations and their potential extinction as a distinct taxon (e.g. Gottelli et al. 1994; Muñoz-Fuentes et al. 2007; Randi 2008).

Vancouver Island, roughly $30,000 \mathrm{~km}^{2}$, is located along the west coast of Canada and is separated from the British Columbian mainland by three channels that are, in places, less than a kilometre wide. Since the 1920s, several attempts were made to eradicate the wolf population on the island, which was thought to be virtually extirpated by 1950 (I. M. Cowan, personal communication; Scott and Shackleton 1982). Between 1950 and 1970 there were infrequent reports of wolves, none of them confirmed. In the 1970s sightings increased, and by 1976 wolves were regularly observed (Hebert et al. 1982; Reid and Janz 1995). Wolves in nearby areas of coastal British Columbia have been observed swimming frequently among landmasses (Darimont and Paquet 2002; Paquet et al. 2006), and so wolves from adjacent coastal British Columbia likely re-colonized Vancouver Island naturally.

The absence of a permanent wolf presence on Vancouver Island between 1950 and 1970 suggests that re-colonization might have been slow. The currents between Vancouver Island and the mainland are strong, and an immigrating wolf would immediately encounter human populations, which are concentrated on the east side of the island. As wolf numbers increased, hunting and trapping were permitted again in 1977 and 1979, respectively. Later, between 1982 and 1986, the provincial government administered a wolf control programme that effectively reduced population size (Reid and Janz 1995).

To test for potential population differentiation in wolves on Vancouver Island through time as a consequence of the extirpation campaigns, we sequenced control region mitochondrial DNA (mtDNA) in samples collected during the twentieth century. Because we found three wolves from 1986 with a domestic dog mtDNA haplotype, we assessed the potential effects of hybridization on the current (post1970s) wolf population on the island. Accordingly, we analysed mtDNA and 13 autosomal microsatellite loci in post-1970s wolves from Vancouver Island and dogs from British Columbia.

\section{Methods}

\section{Materials}

We analyzed 33 wolves from Vancouver Island and 29 dogs from adjacent coastal British Columbia (Table 1). Wolf samples were derived from museum specimens collected between 1910 and $1986(\mathrm{n}=31)$ and fresh samples collected in 2005 and $2007(n=2)$. Tissue was tooth root from museum specimens and muscle and dry skin from animals legally hunted or trapped for reasons other than this study. All dogs were sampled in 2007 for reasons other

Table 1 Samples of dogs and wolves from British Columbia analysed in this study

\begin{tabular}{llcc}
\hline Species & Date & n-mtDNA & n-Microsatellites \\
\hline Dogs & 2007 & 29 & 29 \\
Wolves & $1910-1950$ & $13^{\mathrm{a}}$ & - \\
& 1977 & $1^{\mathrm{b}}$ & - \\
& 1985,1986 & $17^{\mathrm{c}}$ & $17^{\mathrm{d}}$ \\
& 2005,2007 & 2 & 2 \\
\hline
\end{tabular}

\footnotetext{
${ }^{a}$ One sequence in Muñoz-Fuentes et al. (2009)

b Muñoz-Fuentes et al. (2009)

c Fourteen sequences in Muñoz-Fuentes et al. (2009)

d One sample consistently failed to amplify and no reliable microsatellite data were obtained
} 
than this study and included pure and mixed breed dogs; samples were dry blood. They were pets and originated from four different communities (Bella Bella, Klemtu, Ocean Falls and Shearwater) on the mainland.

\section{Sequencing mtDNA control region}

DNA from tooth roots of museum specimens were extracted following the Yang et al. (1998) protocol as in Muñoz-Fuentes et al. (2009). DNA from blood, muscle and skin samples was extracted using the DNeasy Tissue Kit (Qiagen, Hilden, Germany) following the manufacturer's recommendations.

A 425-basepair (bp) fragment of the $5^{0}$ end of the mitochondrial control region was amplified with the primers Thr-L (Vilà et al. 1999) and DLHc (Leonard et al. 2002) as in Muñoz-Fuentes et al. (2009). To obtain sequences for 11 museum samples collected in 1977 or earlier, a variety of internal primers were used in reactions prepared as above and that yielded PCR products between 108 and $311 \mathrm{bp}$ (including primers), combining Thr-L and ddl5.R to obtain a first portion of the fragment, ddl1s.F and ddl2.R to obtain a middle portion, and ddl1s.F, dog3F or dog5F and DLHc to obtain the end portion (see supplementary Table S1). In the case of museum specimens, extraction and PCR negatives were always included to monitor for potential contamination and each sample was sequenced at least twice from independent PCRs. Ambiguities were resolved by sequencing the product of two or more additional independent PCRs. Sequences for three museum wolf samples were approximate because amplification of a portion of the 425-bp fragment consistently failed, resulting in an unresolved $\mathrm{C} / \mathrm{T}$ ambiguity for one sample and either 132 or 150 bp missing for two samples (Table 2).

PCR products were purified in 18-11 reactions containing 1511 of PCR product, $12 \mathrm{U}$ of Exonuclease I (New England Biolabs) and 1.2 U of Shrimp Alkaline Phosphatase (USB Corporation) incubated at $37^{\circ} \mathrm{C}$ for $15 \mathrm{~min}$ followed by $80^{\circ} \mathrm{C}$ for $15 \mathrm{~min}$. Both strands of each PCR product were sequenced with the same primers as used for amplification and then reaction products were separated in an automated sequencer (ABI 3730xl DNA Analyzer, Applied Biosystems). Sequences from multiple PCRs were checked and edited using Sequencher 4.6 (Gene Codes Corporation), and were then aligned by eye using Se-Al v2.0a11 Carbon (Rambaut 1996). Sequences have been submitted to the EMBL/GenBank/DDBJ database (Accession numbers: FN298173-FN298218).

\section{Typing microsatellite loci}

Thirteen unlinked autosomal microsatellite loci, initially developed for dogs, were selected from the literature (Vilà et al. 2003b; Sundqvist et al. 2006) to type 48 individuals (Table 1), and included u109, u173, u225, u250, u253 (Ostrander et al. 1993), vWF (Shibuya et al. 1994), 2006, c2079, c2088, c2096 (Francisco et al. 1996), PEZ3, PEZ5 and PEZ12 (Perkin Elmer, Zoogen). One 3-multiplex with u109, u173 and u225, and two 2-multiplex, one with u250 and vWF and another with c2079 and PEZ3, were performed, whereas all other loci were single-plexed. All samples were amplified by PCR in 10-11 reactions containing 19 Gold Buffer (Applied Biosystems), $2.5 \mathrm{mM}$ $\mathrm{MgCl}_{2}, 1 \mathrm{mM}$ dNTPs (0.25 mM each), $0.51 \mathrm{M}$ each primer (0.4 1M in the case of multiplexes), 10-100 ng of genomic DNA and $0.35 \mathrm{U}$ of AmpliTaq Gold DNA polymerase (Applied Biosystems). PCRs were performed in a PTC-225 (MJ Research) thermocycler with an initial denaturation step of $95^{\circ} \mathrm{C}$ for 5 min followed by 20 cycles of $95^{\circ} \mathrm{C}$ for $30 \mathrm{~s}, 55^{\circ} \mathrm{C}$ for $30 \mathrm{~s}$, and $72^{\circ} \mathrm{C}$ for $1 \mathrm{~min} ; 25$ cycles of $95^{\circ} \mathrm{C}$ for $30 \mathrm{~s}, 52^{\circ} \mathrm{C}$ for $30 \mathrm{~s}$, and $72^{\circ} \mathrm{C}$ for $1 \mathrm{~min}$; and a final extension of $72^{\circ} \mathrm{C}$ for $7 \mathrm{~min}$. In the case of loci 253, 2006, 2088 and the multiplex containing 250 and vWF all cycles were performed with annealing temperature set to $55^{\circ} \mathrm{C}$. For museum specimens and in the case of loci 109, 173, 225, 2079, 2076, PEZ3, PEZ5 and PEZ12 we conducted re-amplifications (three per sample and locus) in single-plexed reactions using $2 \mathbf{1 l}$ of the PCR products previously obtained and following the conditions indicated above. PCR products were electrophoresed on a MegaBACE sequencer (Amersham). Fragment sizes were determined using Genetic Profiler v2.2 (Amersham) by comparison to an internal size standard.

Given the degraded nature of DNA extracts from museum specimens, the risk of allelic dropout and false alleles exists in samples that are just 30 years old (Sefc et al. 2003). Allelic dropout is the no amplification of one of the alleles in a heterozygous individual and a false allele is the amplification of a PCR artifact, both leading to erroneous genotypes if the genotyping is not repeated (Taberlet et al. 1996). To avoid these problems, museum samples were genotyped multiple times from independent PCRs. Heterozygote genotypes were accepted after two identical genotypes were obtained from independent PCRs and homozygote genotypes after three identical genotypes were acquired. For standard PCRs, the rate of dropout per locus ranged between 0 and $41 \%$ and the rate of false alleles ranged between 0 and 3\%; for re-amplifications, the rate was $0-37 \%$ and $0-8 \%$, respectively (Table 3 ). To calculate these, we followed the recommendations of Broquet and Petit (2004).

\section{Data analyses}

To group mtDNA sequences into haplotypes we used TCS version 1.21 (Clement et al. 2000). We then estimated the 
Table 2 Vancouver Island wolf samples analysed in this study a Institutions contributing samples: Cowan, Cowan

Vertebrate Museum; RBCM, Royal British Columbia

Museum

b Sex: F, female; M, male;

?, unknown

c Age: Ad, Adult; Imm, immature; ?, unknown

d Year, month, day (YYYYMMDD)

e Unresolved C/T ambiguity

f Incomplete mtDNA sequence

g Amplifications unsuccessful (no genotype data)

h Published (Muñoz-Fuentes et al. 2009)

\begin{tabular}{|c|c|c|c|c|c|c|}
\hline Specimen code ${ }^{a}$ & $\operatorname{Sex}^{\mathrm{b}}$ & $\operatorname{Age}^{c}$ & $\begin{array}{l}\text { Collection } \\
\text { date }^{\mathrm{d}}\end{array}$ & Tissue & Haplotype & $\begin{array}{l}\text { Microsatellites } \\
\text { attempted? }\end{array}$ \\
\hline RBCM 001441 & ? & Ad & 19100000 & Tooth root & lu68 & No \\
\hline Cowan 6146 & M & ? & 19320326 & Tooth root & $\operatorname{lu} 68^{\mathrm{h}}$ & No \\
\hline RBCM 001862 & $\mathrm{~F}$ & Ad & 19370329 & Tooth root & $\operatorname{lu} 68^{e}$ & No \\
\hline RBCM 001864 & M & Ad & 19370416 & Tooth root & lu68 & No \\
\hline RBCM 001863 & $\mathrm{~F}$ & Ad & 19370417 & Tooth root & lu68 & No \\
\hline RBCM 003339 & M & Ad & 19380800 & Tooth root & lu68 & No \\
\hline RBCM 005304 & $\mathrm{~F}$ & Ad & 19470924 & Tooth root & lu68 & No \\
\hline RBCM 005305 & $?$ & Imm & 19470924 & Tooth root & lu68 & No \\
\hline RBCM 005306 & ? & Imm & 19470924 & Tooth root & $\operatorname{lu} 68^{f}$ & No \\
\hline RBCM 005307 & $?$ & $\operatorname{Imm}$ & 19470924 & Tooth root & $\operatorname{lu} 68 / 38^{f}$ & No \\
\hline RBCM 005647 & M & Ad & 19500225 & Tooth root & lu68 & No \\
\hline RBCM 005648 & $\mathrm{~F}$ & Ad & 19500225 & Tooth root & lu68 & No \\
\hline RBCM 005659 & M & Ad & 19500930 & Tooth root & lu68 & No \\
\hline Cowan 10876 & $\mathrm{~F}$ & & 19771019 & Tooth root & $\operatorname{lu} 38^{h}$ & No \\
\hline RBCM 015382 & M & Ad & 19851005 & Tooth root & $\operatorname{lu} 38^{h}$ & Yes \\
\hline RBCM 015392 & $\mathrm{~F}$ & Ad & 19851024 & Tooth root & $\operatorname{lu} 38^{h}$ & Yes \\
\hline RBCM 016086 & $\mathrm{~F}$ & Ad & 19860000 & Tooth root & Dog & $\mathrm{Yes}^{\mathrm{g}}$ \\
\hline RBCM 016089 & $\mathrm{~F}$ & Imm & 19860000 & Tooth root & Dog & Yes \\
\hline RBCM 016093 & M & Ad & 19860000 & Tooth root & $\operatorname{lu} 38^{\mathrm{h}}$ & Yes \\
\hline RBCM 016094 & M & Ad & 19860000 & Tooth root & $\operatorname{lu} 38^{h}$ & Yes \\
\hline RBCM 016097 & $\mathrm{~F}$ & Ad & 19860000 & Tooth root & Dog & Yes \\
\hline RBCM 016099 & M & $\mathrm{Ad}$ & 19860000 & Tooth root & $\operatorname{lu} 38^{h}$ & Yes \\
\hline RBCM 016100 & $\mathrm{~F}$ & $\mathrm{Ad}$ & 19860000 & Tooth root & $\operatorname{lu} 38^{h}$ & Yes \\
\hline RBCM 016103 & M & ? & 19860000 & Tooth root & $\operatorname{lu} 38^{h}$ & Yes \\
\hline RBCM 015387 & $\mathrm{~F}$ & $\mathrm{Ad}$ & 19860104 & Tooth root & $\operatorname{lu} 38^{h}$ & Yes \\
\hline RBCM 015386 & M & $\mathrm{Ad}$ & 19860127 & Tooth root & $\operatorname{lu} 38^{h}$ & Yes \\
\hline RBCM 015771 & $\mathrm{~F}$ & $\mathrm{Ad}$ & 19860302 & Tooth root & $\operatorname{lu} 38^{\mathrm{h}}$ & Yes \\
\hline RBCM 015766 & $\mathrm{M}$ & $\mathrm{Ad}$ & 19860601 & Tooth root & $\operatorname{lu} 38^{\mathrm{h}}$ & Yes \\
\hline RBCM 015765 & $\mathrm{~F}$ & $\mathrm{Ad}$ & 19860605 & Tooth root & $\operatorname{lu} 38^{\mathrm{h}}$ & Yes \\
\hline RBCM 015775 & M & Ad & 19860626 & Tooth root & $\operatorname{lu} 38^{\mathrm{h}}$ & Yes \\
\hline RBCM 015777 & $\mathrm{M}$ & Imm & 19860716 & Tooth root & $\operatorname{lu} 38^{h}$ & Yes \\
\hline JAL 5171 & $?$ & $?$ & 20051100 & Muscle & lu38 & Yes \\
\hline JAL 5172 & M & Ad & 20070300 & Muscle & lu38 & Yes \\
\hline
\end{tabular}

number of female founders that could have re-colonized Vancouver Island. Three haplotypes were found in the adjacent mainland (Muñoz-Fuentes et al. 2009). We sampled a given number of individuals (potential founders) from that dataset 1,000 times, and counted the number of times (out of 1,000) one, two or three haplotypes were recovered. Because only one haplotype is present in the contemporary wolf population on Vancouver Island, we assumed that a certain number of founders (and any number above this one) was unlikely when it would result in the arrival of more than one haplotype in at least $95 \%$ of the 1,000 re-samplings $(\mathrm{P}=0.05)$.

We tested the microsatellite data for Hardy-Weinberg equilibrium and linkage disequilibrium with GENEPOP on the web (Raymond and Rousset 1995) and applied the false discovery rate method (Benjamini and Hochberg 1995) to evaluate statistical significance when multiple simultaneous tests are performed. We checked for genotyping errors with MICRO-CHECKER version 2.2.1 (Van Oosterhout et al. 2004). We used a factorial correspondence analysis (FCA) in GENETIX version 4.0.5.2 (Belkhir et al. 1996-2004) to plot each individual in a two-dimensional space according to their microsatellite allele composition independent of any a priori species designations. We used HP-RARE v. June-6-2006 (Kalinowski 2005) to correct allelic richness values for differences in sample size.

We used a Bayesian clustering method as implemented in STRUCTURE version 2.2 (Pritchard et al. 2000) to identify the most likely number of populations $(\mathrm{K})$ and to assign probabilistically individuals to populations without 
Table 3 Rate of dropout and false alleles for each locus genotyped in post-1970 wolf museum specimens in this study

\begin{tabular}{|c|c|c|c|c|c|c|c|c|c|}
\hline \multirow[t]{2}{*}{ Locus } & \multirow[t]{2}{*}{ Size (bp) } & \multicolumn{4}{|c|}{ Standard PCRs } & \multicolumn{4}{|c|}{ Re-amplifications } \\
\hline & & $\mathrm{n}$ & Successful & Dropout & False & $\mathrm{n}$ & Successful & Dropout & False \\
\hline 109 & $140-150$ & 117 & 0.29 & 0.19 & 0 & 51 & 0.69 & 0.29 & 0.03 \\
\hline 173 & $102-112$ & 67 & 0.37 & 0 & 0 & 51 & 0.94 & 0.06 & 0.08 \\
\hline 225 & $163-169$ & 111 & 0.38 & 0.06 & 0 & 51 & 0.59 & 0.38 & 0.03 \\
\hline 250 & 127-139 & 58 & 0.90 & 0.03 & 0 & 0 & - & - & - \\
\hline 253 & $106-110$ & 101 & 0.60 & 0.02 & 0 & 0 & - & - & - \\
\hline 2006 & 187-191 & 103 & 0.83 & 0.41 & 0.03 & 0 & - & - & - \\
\hline 2079 & 276-280 & 78 & 0.45 & 0 & 0 & 51 & 0.71 & 0.00 & 0 \\
\hline 2088 & $116-128$ & 97 & 0.86 & 0 & 0 & 0 & - & - & - \\
\hline 2096 & 99-103 & 54 & 0.15 & 0.25 & 0 & 51 & 0.88 & 0.00 & 0 \\
\hline PEZ12 & 256-296 & 94 & 0.51 & 0.12 & 0.02 & 51 & 0.59 & 0.14 & 0.03 \\
\hline PEZ3 & 117-142 & 59 & 0.39 & 0 & 0 & 51 & 0.80 & 0.00 & 0 \\
\hline PEZ5 & $96-112$ & 74 & 0.53 & 0.06 & 0.03 & 51 & 0.86 & 0.11 & 0 \\
\hline vWF & 157-181 & 58 & 0.88 & 0.08 & 0 & 0 & - & - & - \\
\hline Total & & 1,071 & 0.55 & 0.10 & 0.01 & 408 & 0.76 & 0.12 & 0.02 \\
\hline
\end{tabular}

Size, allele size in base pairs (bp); n, the number of PCRs performed; Successful, the number of PCRs for which a genotype was obtained; Dropout, allelic dropout; False, false alleles

using a priori information on sampling location. Ten runs were completed for each value of $\mathrm{K}$ (from 1 to 4 ) using 30,000 steps for burnin length and 300,000 steps for run length and we asked the programme to calculate $90 \%$ probability regions for each inferred cluster. The likelihood values converged during runs, and ten runs for each value of $\mathrm{K}$ yielded almost identical results. All individuals for which microsatellite data were available were included in these analyses.

We also used a Bayesian assignment method, as implemented in the software NEWHYBRIDS version 1.1 beta (Anderson and Thompson 2002), to identify pure individuals and distinguish among hybrid types. This approach makes no a priori assumptions about population allele frequencies. We set NEWHYBRIDS to distinguish the two parental species, F1s, F2s, and first-generation backcrosses to each of the parental species. No a priori information about the origin of individuals morphologically identified as wolves was entered into the analysis, while the dogs were reported to belong to one of the parental species. As recommended in the manual, we ran the program with different priors to explore the sensitivity of the results.

Finally, to characterize the genetic heterogeneity of the Vancouver Island wolf population, we used MICROSATELLITE TOOLKIT (Park 2001) to obtain the percentage of shared alleles between each pair of individuals. A bimodal distribution would indicate that wolves in Vancouver Island had different origins based on their nuclear DNA, potentially reflecting that the wolf population had been unevenly affected by dog introgression, which would suggest it had been recent.
Results

\section{MtDNA}

We found three haplotypes among the 33 Vancouver Island wolves, two of which, lu38 and lu68, were previously reported in British Columbia coastal wolves (Muñoz-Fuentes et al. 2009). The remaining one was found in dogs. Among the wolves collected between 1910 and 1950, 12 had haplotype lu68 and one individual had an incomplete sequence which was compatible with being either lu68 or lu38 (these two haplotypes only differ in one substitution), but incompatible with being any of the dog haplotypes (Table 2). The remaining wolves, collected in 1977 or later, had either haplotype lu38 ( $\mathrm{n}=17$ ) or the dog haplotype $(n=3)$ (Table 2$)$. Those with the dog haplotype were killed in the same year (1986) in two different locations, roughly $75 \mathrm{~km}$ apart, and were females, two adults and one immature.

Among the 29 dogs analysed from coastal British Columbia, we observed 12 haplotypes. Of these, the abovementioned dog haplotype was most common ( $n=6 ; 21 \%)$. Two haplotypes were found each in five dogs $(17 \%)$, one haplotype in four dogs (14\%), one in two dogs (7\%), and seven haplotypes were found each in one individual.

The haplotype found in the sample of dogs and wolves is separated by 11 substitutions from lu38 (12 in the case of lu68) and has only been reported in dogs previously (Accession numbers: U96639.2; AY656747.1; AY656755.1; AY706485.1; AY706523.1; DQ480495.1). It has previously been phylogenetically assigned to Clade I of the dog 
mitochondrial haplotypes (Vilà et al. 1997; Björnerfeldt et al. 2006).

Based on the mtDNA haplotype frequencies found in the British Columbia mainland (Muñoz-Fuentes et al. 2009), a re-sampling analysis indicated that the probability of finding more than one wolf haplotype in Vancouver Island surpassed $95 \%$ at eight female founders. Because a single wolf haplotype was identified in the current post-1970s population, it is probable that $\backslash 8$ female wolves successfully reproduced to found the contemporary Vancouver Island wolf population (Table 4).

\section{Microsatellites}

A total of 56 alleles were found in 19 wolves from Vancouver Island and 86 in 29 dogs from British Columbia (see supplementary Table S2 for allele frequencies). When correcting for unequal sample sizes, 76 alleles were estimated for dogs. Nine private alleles were found in wolves and 39 private alleles in dogs, present in 6 and 13 loci, respectively. Again correcting for unequal sample sizes, 33 private alleles were estimated for dogs. The number of alleles per locus ranged from 2 to 9 in wolves and 4 and 13 in dogs. In the case of three loci (loci 253, 2006 and 2079) the most frequent allele was the same in both species; for the remaining loci, the most frequent allele in one species was present in the other. One sample corresponding to one of the three wolves that had a dog mtDNA haplotype consistently failed to amplify; only six loci could be genotyped once and so we excluded this sample from the analyses.

MICRO-CHECKER found no evidence for scoring errors due to stuttering or large allele dropout, but found excess of homozygotes in dogs for loci 2006, 173, 250 and vWF. After statistical correction for multiple comparisons, there was significant evidence that one locus, 2006, was not in HardyWeinberg equilibrium for dogs, but no evidence for linkage disequilibrium was found in either dogs or wolves. Locus 2006 was excluded from subsequent analyses.

A FCA identified two clusters in a two-dimensional space based on the genotypes of dogs and wolves, with

Table 4 Number of wolves re-sampled from the mainland 1,000 times and observed number of replicates with a single haplotype

\begin{tabular}{lcc}
\hline $\begin{array}{l}\text { Number of wolves } \\
\text { re-sampled }\end{array}$ & $\begin{array}{l}\text { Number of replicates } \\
\text { with a single haplotype }\end{array}$ & $\mathrm{P}$ \\
\hline 1 & 1,000 & 1.00 \\
3 & 300 & 0.30 \\
5 & 137 & 0.14 \\
6 & 86 & 0.09 \\
7 & 90 & 0.09 \\
8 & 35 & 0.04 \\
\hline
\end{tabular}

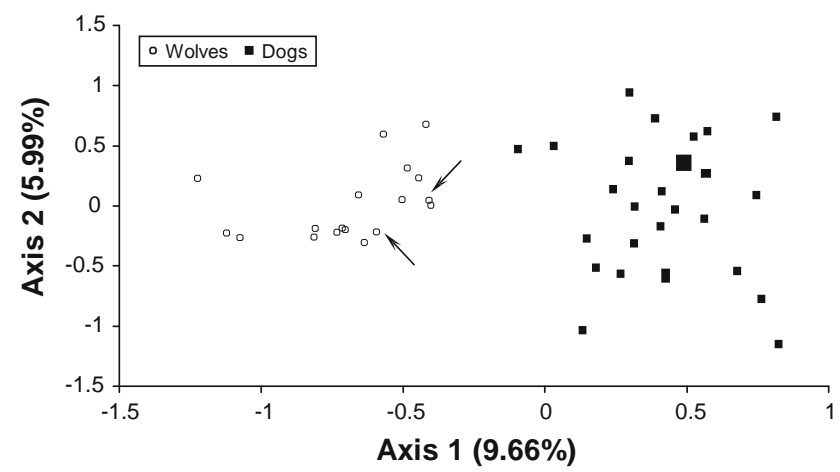

Fig. 1 Factorial correspondence analysis based on the genotypes of post-1970 Vancouver Island wolves and contemporary British Columbia dogs analysed in this study. The arrows indicate two individuals morphologically identified as wolves that had dog mtDNA

dogs assigning to one cluster and wolves to another (Fig. 1). The two wolves with dog mtDNA that was possible to genotype clustered within the wolves and were not more closely related to one another than to other wolves in the population.

STRUCTURE identified two groups $(K=2)$ as the most probable (Ln of prob of data $=-1610.3$ ) and strongly assigned dogs to one group and individuals morphologically identified as wolves to another, including the two wolves with dog mtDNA (Fig. 2). For all individuals except two dogs and two wolves (91\% of the samples), the inferred proportion of ancestry to their respective population was [90\%, with probability intervals oscillating between $0.6-0.96$ and 1 for either dogs or wolves (see supplementary Table S3 for results). For the two remaining wolves it was 79 and $78 \%$ (probability intervals $0.4-1$ ) and for the two remaining dogs it was $89 \%(0.5-1)$ and $74 \%$ $(0.3-1)$. The two wolves with dog mtDNA had $95 \%$ of ancestry attributed to the wolf population and had probability intervals between 0.7 and 1 . The results obtained from NEWHYBRIDS differed for different combinations of priors for both wolves and dogs, and so were considered unreliable according to the software manual.

We plotted the percentage of alleles shared by wolf pairs sampled in 1985 and 1986 and a unimodal distribution was observed (Fig. 3), indicating that the Vancouver Island wolf population is uniform in respect to genotypes, suggesting that the dog introgression was early in the re-colonization process.

\section{Discussion}

Vancouver Island wolves through time

MtDNA data showed a turnover in wolf haplotype composition following the period of intense persecution by 


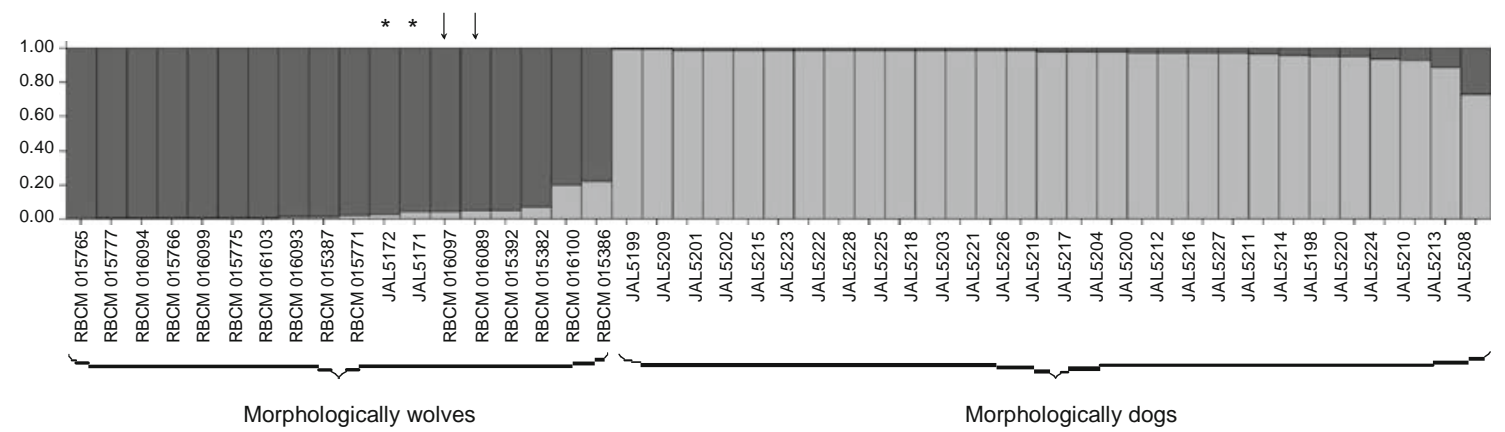

Fig. 2 Bar plot of Structure based on the genotypes of post-1970 Vancouver Island wolves and contemporary British Columbia dogs analysed in this study. Individuals morphologically identified as wolves were eliminated from the population in $1985(\mathrm{n}=2)$ and $1986(\mathrm{n}=14)$, except for two marked with an asterisk $(*)$ killed in 2005 and 2007. The arrows indicate two individuals morphologically

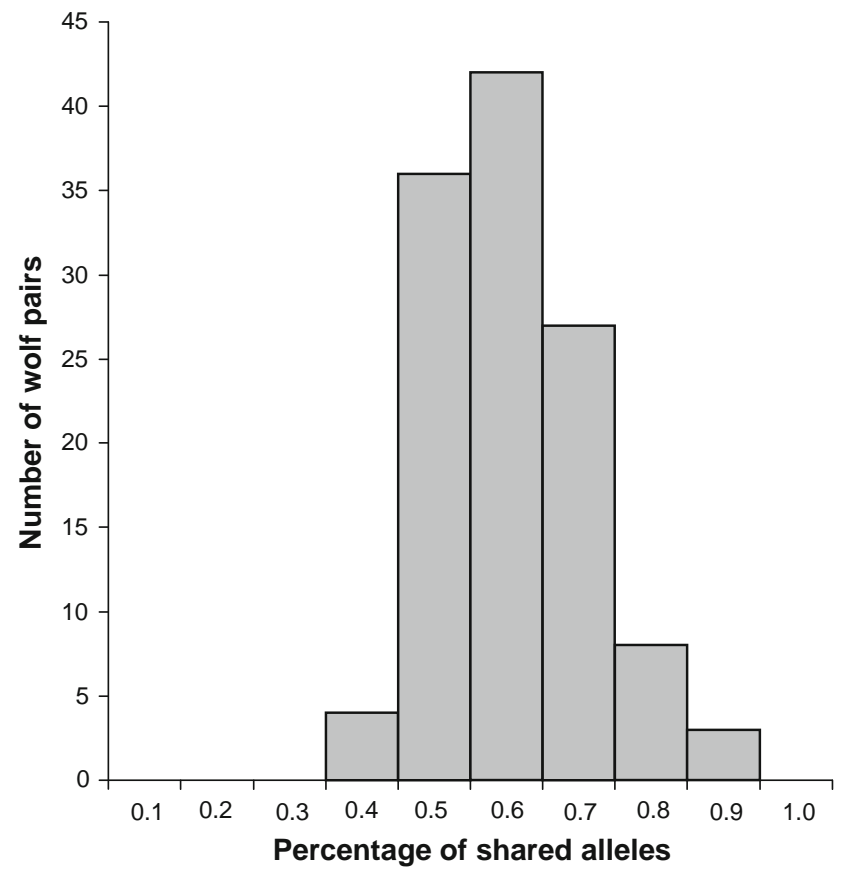

Fig. 3 Percentage of alleles shared by wolves sampled in Vancouver Island between 1985 and 1986

humans. We detected only haplotype lu68 among wolves killed between 1910 and 1950, whereas wolves killed in 1977 or later had haplotype lu38. These haplotypes are the most frequent (18.7 and $76 \%$, respectively) in coastal wolves from adjacent mainland British Columbia, while another one was less frequent (5.3\%) and found in the north and the south of the coastal area (Muñoz-Fuentes et al. 2009). The combination of infrequent wolf reports that were never confirmed during the 1950s and 1960s on Vancouver Island (Reid and Janz 1995) and the replacement of the mtDNA haplotype strongly supports the hypothesis of a local extinction of wolves on Vancouver Island during this time, followed by a re-colonization by identified as wolves that had dog mtDNA. The most probable structure is based on two groups $(\mathrm{K}=2)$. Each bar represents an individual and the coloured area is proportional to the relative amount of ancestry attributed to the wolf (black) or the dog (light grey) population based on the individual's genotype

mainland wolves. Our re-sampling analysis indicates that likely $\backslash 8$ females arrived to reproduce on Vancouver Island, suggesting that re-colonization of the island by wolves from the mainland is a rare event and little gene flow is present. The rarity of colonization is also supported by the long period $(* 20$ years) in which wolves were not established on the island.

\section{Hybridization on Vancouver Island}

The presence of a domestic dog mtDNA haplotype in individuals morphologically identified as wolves, implies that at least one hybridization event took place on Vancouver Island. Our data suggest that a female dog or a female hybrid with dog mtDNA must have mated with a male wolf and successfully raised at least one female offspring to become subsequently a reproductive female in the population. In a small population where individuals are recolonizing, a hybrid female may have higher chances of reproducing due to limited mate availability (Allee effect).

Obstacles to male wolf-female dog hybridization are not only behavioural, but also physiological (Vilà and Wayne 1999). Male wolves have seasonal sperm production and overlap in time with female wolves coming into oestrus between late January and April, while male dogs produce sperm all year round and female dogs have two oestrus periods each year that may occur in any month. Therefore, when male wolves are able to mate, the frequency of female wolves in oestrus should outnumber the number of female dogs in oestrus. Consequently, opportunities for a female dog to mate with a male wolf would normally be infrequent (Vilà and Wayne 1999). Notably, despite behavioural and physiological obstacles to the mating of wolves and domestic dogs, ecological and social conditions were met on Vancouver Island that allowed hybridization to take place. 
Autosomal microsatellite data showed that wolves and dogs formed two distinct clusters (FCA, Fig. 1; Structure, Fig. 2). Two wolves eliminated from the population in 1986 that had wolf mtDNA were identified by STRUCTURE as having 23 and $21 \%$ dog ancestry with probability intervals between 0 and 0.6. However, a pure-breed dog was identified as having $27 \%$ wolf ancestry with probability regions between 0 and 0.7. These results together with the inconsistent NEWHYBRIDS' results, do not allow us to say with certainty whether these two individuals were backcrosses to wolves or pure wolves. The lack of F1s and the presence of two or none backcrosses in wolves from 1985 to 2007 indicates that hybridization of wild wolves with dogs is a rare event and has not occurred recently. We also note that all wolf samples correspond to dead individuals and therefore are no longer present in the population.

The three individuals with dog mtDNA were morphologically identified as female wolves and the two of them for which nuclear data could be collected clustered with the wolves based on genotype data. Because we found that wolves with introgressed mtDNA haplotypes had wolf genotypes, the hybridization event must have happened several generations ago, likely early in the colonization process of Vancouver Island. If hybridization had occurred after 1976, when wolves were abundant on the island, it would have affected the population unevenly. The uniform genetic composition of the wolf population on the island (Fig. 3) further suggests that hybridization did not take place recently. It is unlikely that wolves or hybrids came from the southernmost part of coastal British Columbia, because wolves have been extirpated for more than a century from this area. The likely source of the founders for the contemporary Vancouver Island wolf population is north of this area. This region and the island-network in between the mainland and Vancouver Island constitute a largely unsettled area where very few humans (and dogs) live. Importantly, large-scale wolf control never occurred in this area, making hybridization unlikely. Moreover, wolves have been intensively sampled from coastal British Columbia and among analysed museum samples from the 1930s and 1940s $(n=7)$, contemporary tissue $(n=3)$ and faeces $(n=67)$, only one dog mtDNA sequence was detected in a faecal sample, which was likely deposited by a dog in a wilderness area (Muñoz-Fuentes et al. 2009).

Therefore, the lines of evidence presented above (behavioural and physiological difficulties, lack of F1s, dog mtDNA in individuals with a wolf genotype, homogeneous wolf population and no support for hybrids coming from the mainland) support the hypothesis that the hybridization event occurred as the first males were re-colonizing Vancouver Island, before any/many females arrived. Under this scenario, the only option for one or several male wolves might have been to mate with a feral female dog or wolf-dog hybrid, or to forgo breeding altogether. Once wolves became more abundant, behavioural and physiological mechanisms favoured mating of wolves with each other.

The population expanded quickly after the mid 1970s, which may suggest the arrival of one or more additional wolves from the mainland to the Island. The arrival of a single immigrant to the isolated and small Scandinavian population, previously founded by a single male and female, lead to an increase in heterozygosity and in the number of wolf packs, to the rapid incorporation of new alleles and to exponential population growth (Vilà et al. 2003b).

Despite the large number of wolf populations genetically characterized in both Europe and North America (see "Introduction"), in many cases heavily hunted and persecuted, to our knowledge this is the first time a domestic dog haplotype has been found in a wolf population. This suggests that unusual ecological and social conditions have to be met for this to occur.

\section{Conservation implications}

Despite the presence of a domestic dog mtDNA haplotype in the wolf population of Vancouver Island, the wolf and dog populations were distinct and no evidence of ongoing hybridization was identified. Because the wolf population is morphologically, behaviourally and genetically distinct from the dog population, the wolves deserve full recognition and protection as a population of wild wolves.

Notably, our data suggest that human-caused population declines or extirpations can set the conditions for hybridization between wild wolves and domestic dogs to occur. It is unknown whether the presence of dog mtDNA in these wolves may have any phenotypic effect, but it nonetheless demonstrates the possibility that male wolves and female dogs can produce offspring, which under some circumstances could backcross into the wild wolf population. These conditions likely depend on very small population size. Hybridization with dogs may disrupt wolves' specific adaptations (behavioural, physiological and potentially others) and should therefore be avoided. The observation of introgressed dog mtDNA into Vancouver Island wolves highlights the importance of maintaining population sizes that are sufficient to avoid Allee effects. In addition, small wild populations may suffer from inbreeding depression (Spielman et al. 2004; Charpentier et al. 2008). Accordingly, management objectives and actions that seek to reduce wolf populations may be in conflict with prudent conservation policies.

Likewise, this issue is important when planning for other small wild canid populations, such as reintroduced Mexican and red wolves in North America. The Mexican wolf 
population (Canis lupus baileyi) has been kept at $40-50$ individuals during the past several years at its reintroduction site in Arizona and New Mexico (USA) and no current prospects exist for it to be increased (Hedrick and Fredrickson 2008). The red wolf (Canis rufus) population of 100 individuals now present at North Carolina (USA) might be similarly threatened; in fact, hybridization with coyotes was identified in the population as a threat to the survival of the species and is currently managed (Adams et al. 2007; Hedrick and Fredrickson 2008). Hybridization issues, such as the one presented here, could become a concern in dramatically small and altered canid populations. To avoid them, management actions should aim at increasing population sizes.

Acknowledgments We thank Heather Bryan for sharing dog samples with us and to Helen Schwantje of the British Columbia Ministry of Environment for providing contemporary wolf samples. We thank Rex Kenner of the University of British Columbia Cowan Vertebrate Museum and Jim Cosgrove from the Royal British Columbia Museum for access to samples in collections. We are also thankful to Carles Vilà and Robert K. Wayne for a critical reading of the manuscript. Funding was provided by the European Union Marie Curie Fellowship programme, the National Science and Engineering Research Council of Canada Postdoctoral Fellowship programme, the National Science Foundation, USA (OPP-0352634), the Spanish Ministry of Education, the Swedish Research Council, Raincoast Conservation Foundation, Wilburforce Foundation and World Wildlife FundCanada. The Center for Conservation \& Evolutionary Genetics, National Zoological Park, Smithsonian Institution, USA, provided logistical support.

\section{References}

Adams JR, Leonard JA, Waits LP (2003) Widespread occurrence of a domestic dog mitochondrial DNA haplotype in southeastern US coyotes. Mol Ecol 12:541-546. doi:10.1046/j.1365-294X.2003. 01708. $\mathrm{x}$

Adams JR, Lucash C, Schutte L, Waits LP (2007) Locating hybrid individuals in the red wolf (Canis rufus) experimental population area using a spatially targeted sampling strategy and faecal DNA genotyping. Mol Ecol 16:1823-1834. doi:10.1111/j.1365-294X. 2007.03270.x

Allee WC (1931) Animal aggregations. University of Chicago Press, Chicago

Anderson EC, Thompson EA (2002) A model-based method for identifying species hybrids using multilocus genetic data. Genetics 160:1217-1229

Andersone Z, Lucchini V, Randi E, Ozolins J (2002) Hybridisation between wolves and dogs in Latvia as documented using mitochondrial and microsatellite DNA markers. Mammal Biol 67:79-90. doi:10.1078/1616-5047-00012

Belkhir K, Borsa P, Chikhi L, Raufaste N, Bohomme F (1996-2004) GENETIX 4.05, logiciel sous Windows TM pour la génétique des populations. Laboratoire Génome, Populations, Interactions, CNRS UMR 5000, Université de Montpellier II, Montpellier, France. URL: http://www.genetix.univ-montp2.fr/genetix/genetix. htm, last accessed: 26th January 2009
Benjamini Y, Hochberg Y (1995) Controlling the false discovery rate: a practical and powerful approach to multiple testing. J R Stat Soc B 57:289-300

Bibikov D (1982) Wolf ecology and management in the USSR. In: Harrington FH, Paquet P (eds) Wolves of the world. Noyes, Park Ridge, pp 120-133

Björnerfeldt S, Webster MT, Vilà C (2006) Relaxation of selective constraint on dog mitochondrial DNA following domestication. Genome Res 16:990-994. doi:10.1101/gr.5117706

Boitani L (1982) Wolf management in intensively used areas of Italy. In: Harrington FH, Paquet P (eds) Wolves of the world. Noyes, Park Ridge, pp 158-172

Broquet T, Petit M (2004) Quantifying genotyping errors in noninvasive population genetics. Mol Ecol 13:3601-3608. doi: 10.1111/j.1365-294X.2004.02352.x

Charpentier MJE, Williams CV, Drea CM (2008) Inbreeding depression in ring-tailed lemurs (Lemur catta): genetic diversity predicts parasitism, immunocompetence and survivorship. Conserv Genet 9:1605-1615. doi:10.1007/s10592-007-9499-4

Clement M, Posada D, Crandall KA (2000) TCS: a computer program to estimate gene genealogies. Mol Ecol 9:1657-1660. doi: 10.1046/j.1365-294x.2000.01020.x

Darimont CT, Paquet PC (2002) The gray wolves, Canis lupus, of British Columbia's central and north coast: distribution and conservation assessment. Can Field Nat 116:416-422

Francisco LV, Langston AA, Mellersh CS, Neal CL, Ostrander EA (1996) A class of highly polymorphic tetranucleotide repeats for canine genetic mapping. Mamm Genome 7:359-362. doi: 10.1007/s003359900104

Gottelli D, Sillerozubiri C, Applebaum GD, Roy MS, Girman DJ, García-Moreno J, Ostrander EA, Wayne RK (1994) Molecular genetics of the most endangered canid - the Ethiopian wolf Canis simensis. Mol Ecol 3:301-312. doi:10.1111/j.1365-294X.1994. tb00070.x

Hebert DH, Youds J, Davies R, Langin H, Janz D, Smith GW (1982) Preliminary investigations of the Vancouver Island wolf (Canis lupus crassodon) prey relationships. In: Harrington FH, Paquet P (eds) Wolves of the world. Noyes, Park Ridge, pp 54-68

Hedrick PW, Fredrickson RJ (2008) Captive breeding and the reintroduction of Mexican and red wolves. Mol Ecol 17:344350. doi:10.1111/j.1365-294X.2007.03400.x

Kalinowski ST (2005) HP-RARE 1.0: a computer program for performing rarefaction on measures of allelic richness. Mol Ecol Notes 5:187-189. doi:10.1111/j.1471-8286.2004.00845.x

Leonard JA, Wayne RK, Wheeler J, Valádez R, Guillén S, Vilà C (2002) Ancient DNA evidence for old world origin of new world dogs. Science 298:1613-1616. doi:10.1126/science.1076980

Mendelssohn H (1982) Wolves in Israel. In: Harrington FH, Paquet P (eds) Wolves of the world. Noyes, Park Ridge, pp 173-194

Muñoz-Fuentes V, Vilà C, Green AJ, Negro JJ, Sorenson M (2007) Hybridization between white-headed ducks and introduced ruddy ducks in Spain. Mol Ecol 16:629-638. doi:10.1111/j. 1365-294X.2006.03170.x

Muñoz-Fuentes V, Darimont CT, Wayne RK, Paquet P, Leonard JA (2009) Ecological factors drive differentiation in wolves from British Columbia. J Biogeogr 36:1516-1531. doi:10.1111/j. 1365-2699.2008.02067.x

Ostrander EA, Sprague GF Jr, Rine J (1993) Identification and characterization of dinucleotide repeat (CA)n markers for genetic mapping in the dog. Genomics 16:207-332. doi:10.1006/ geno.1993.1160

Paquet PC, Alexander SM, Swan PL, Darimont CT (2006) The influence of natural landscape fragmentation and resource availability on connectivity and distribution of marine gray wolf (Canis lupus) populations on the Central Coast, British Columbia, Canada. In: Crooks K, Sanjayan MAE (eds) Connectivity 
conservation. Society for Conservation Biology. Cambridge University Press, Cambridge, pp 130-156

Park SDE (2001) Trypanotolerance in West African cattle and the population genetic effects of selection. Ph. D. Thesis, University of Dublin, Dublin, Ireland. URL: http://www.animalgenomics. ucd.ie/sdepark/ms-toolkit/, last accessed: 26th January 2009

Pritchard JK, Stephens M, Donnelly P (2000) Inference of population structure using multilocus genotype data. Genetics 155:945-959

Rambaut A (1996) Se-Al: Sequence alignment editor. Department of Zoology, University of Oxford, UK. URL: http://tree.bio.ed. ac.uk/software/seal/, last accessed: 26th January 2009

Randi E (2008) Detecting hybridization between wild species and their domesticated relatives. Mol Ecol 17:285-293. doi: 10.1111/j.1365-294X.2007.03417.x

Randi E, Lucchini V (2002) Detecting rare introgression of domestic dog genes into wild wolf (Canis lupus) populations by Bayesian admixture analyses of microsatellite variation. Conserv Genet 3:31-45. doi:10.1023/A:1014229610646

Randi E, Lucchini V, Christensen MF, Mucci N, Funk SM, Dolf G, Loeschcke V (2000) Mitochondrial DNA variability in Italian and East European wolves: detecting the consequences of small population size and hybridization. Conserv Biol 14:464-473. doi:10.1046/j.1523-1739.2000.98280.x

Raymond M, Rousset F (1995) Genepop (Version-1.2)—population genetics software for exact tests and ecumenicism. J Hered $86: 248-249$

Reid R, Janz D (1995) Economic evaluation of Vancouver Island wolf control. In: Carbyn L, Fritts S, Seip D (eds) Ecology and conservation of wolves in a changing world. Canadian Circumpolar Institute, Occasional Publication No. 35, University of Alberta, Edmonton, Alberta, Canada

Scott BMV, Shackleton DM (1982) A preliminary study of the social organization of the Vancouver Island wolf. In: Harrington $\mathrm{FH}$, Paquet P (eds) Wolves of the world. Noyes, Park Ridge, pp 12-25

Sefc KM, Payne RB, Sorenson MD (2003) Microsatellite amplification from museum feather samples: effects of fragment size and template concentration on genotyping errors. Auk 120:982-989. doi:10.1642/0004-8038(2003)120[0982:MAFMFS]2.0.CO;2

Shibuya H, Collins BK, Huang TH-M, Johnson GS (1994) A polymorphic (AGGAAT)n tandem repeat in an intron of the canine von Willebrand factor gene. Anim Genet 25:122

Spielman D, Brook BW, Frankham R (2004) Most species are not driven to extinction before genetic factors impact them. Proc Natl Acad Sci USA 101:15261-15264. doi:10.1073/pnas.0403 809101
Stephens PA, Sutherland WJ, Freckleton RP (1999) What is the Allee effect? Oikos 87:185-190. doi:10.2307/3547011

Sundqvist A-K, Björnerfeldt S, Leonard JA, Hailer F, Hedhammar A, Ellegren H, Vilà C (2006) Unequal contribution of sexes in the origin of dog breeds. Genetics 172:1121-1128

Taberlet P, Griffin S, Goossens B, Questiau S, Manceau V, Escaravage N, Waits LP, Bouvet J (1996) Reliable genotyping of samples with very los DNA quantities using PCR. Nucleic Acids Res 24:3189-3194. doi:10.1093/nar/24.16.3189

Van Oosterhout C, Hutchinson WF, Wills DPM, Shipley P (2004) MICRO-CHECKER: software for identifying and correcting genotyping errors in microsatellite data. Mol Ecol Notes 4:535538. doi:10.1111/j.1471-8286.2004.00684.x

Verardi A, Lucchini V, Randi E (2006) Detecting introgressive hybridization between free-ranging domestic dogs and wild wolves (Canis lupus) by admixture linkage disequilibrium analysis. Mol Ecol 15:2845-2855

Vilà C, Wayne RK (1999) Hybridization between wolves and dogs. Conserv Biol 13:195-198. doi:10.1046/j.1523-1739.1999.974 25. $\mathrm{x}$

Vilà C, Savolainen P, Maldonado JE, Amorim IR, Rice JE, Honeycutt RL, Crandall KA, Lundeberg J, Wayne RK (1997) Multiple and ancient origins of the domestic dog. Science 276:1687-1689. doi:10.1126/science.276.5319.1687

Vilà C, Amorim IR, Leonard JA, Posada D, Castroviejo J, PetrucciFonseca F, Crandall KA, Ellegren H, Wayne RK (1999) Mitochondrial DNA phylogeography and population history of the grey wolf Canis lupus. Mol Ecol 8:2089-2103. doi: 10.1046/j.1365-294x.1999.00825.x

Vilà C, Sundqvist A-K, Flagstad Ø, Seddon J, Björnerfeldt S, Kojola I, Casulli A, Sand H, Wabakken P, Ellegren H (2003a) Rescue of a severely bottlenecked wolf (Canis lupus) population by a single immigrant. Proc R Soc Lond B Biol Sci 270:91-97. doi: 10.1098/rspb.2002.2184

Vilà C, Walker C, Sundqvist AK, Fagstad Ø, Andersone Z, Casulli A, Kojola I, Valdmann H, Halverson J, Ellegren H (2003b) Combined use of maternal, paternal and bi-parental genetic markers for the identification of wolf-dog hybrids. Heredity 90:17-24. doi:10.1038/sj.hdy.6800175

Yang DY, Eng B, Waye JS, Saunders SR (1998) Technical note: improved DNA extraction from ancient bones using silica-based spin columns. Am J Phys Anthropol 105:539-543. doi:10.1002/ (SICI)1096-8644(199804)105:4 539:AID-AJPA10 [3.0.CO;2-1

Young SP, Goldman EA (1944) The wolves of North America. Dover, New York 